\title{
HISTÓRIA ORAL: REFLEXÕES SOBRE APLICAÇÕES E IMPLICAÇÕES
}

\author{
Oral History: discussions about applications and implications
}

\author{
Samantha Castelo Branco'
}

\section{Resumo}

Nas diferentes áreas do conhecimento, pesquisadores dispõem de variadas opções metodológicas para realizar suas investigações. A História Oral (HO) emerge como possibilidade metodológica em meados do século $X X$ e, no caso brasileiro, vem sendo utilizada em estudos científicos desde a década de 1970. Diretamente associada à noção de memória, esse método se apoia em testemunhos e depoimentos orais, possibilitando a manifestação de fontes normalmente excluídas dos relatos oficiais. Nesse sentido, este artigo objetiva abordar a HO como opção metodológica, bem como refletir sobre suas aplicações e implicações, além de problematizar aspectos éticos e técnicos relacionados a essa metodologia. Recorrendo-se à pesquisa bibliográfica, a partir de autores como Alberti (1990, 2005), Joutard (1999; 2006), Meihy (2002; 2006), Portelli (2001; 2016) e Thompson (2002), expõe-se, ainda, orientações que podem ser adotadas pelos pesquisadores nas fases de planejamento, coleta e análise dos depoimentos, de modo que o entrevistador prime pelo seu papel dialógico e possa conferir, à produção de conhecimento, riqueza e profundidade.

Palavras-chave: História Oral; Metodologia; Aplicações; Limites.

\begin{abstract}
In different areas of knowledge, researchers have several methodological options to carry out their investigations, The Oral History emerges as a methodological possibility in the midtwentieth century in Brazil, this methodology has been used in scientific studies since the 1970s. The Oral history is directly associated with the notion of memory, this method is based on oral testimonies, allowing the expression of sources that are normally excluded from official reports. At this point, this article aims to address oral history as a methodology, as well as reflect on their applications and implications, in addition to problematizing ethical and technical aspects related to the methodology. Using bibliographic research, from authors such as Alberti (1990, 2005), Joutard (1999; 2006), Meihy (2002; 2006), Portelli (2001; 2016) and Thompson (2002), it also sets out guidelines that can be adopted by researchers in the planning stages for the collection and analysis of testimonies, so that the

\footnotetext{
1 Samantha Viana Castelo Branco Rocha Carvalho. Jornalista e advogada. Doutora em Comunicação Social pela Universidade Metodista de São Paulo (UMESP). Professora do Departamento de Comunicação Social (DCS) e do Programa de Pós-graduação em Comunicação (PPGCOM) da Universidade Federal do Piauí (UFPI). Chefe da Unidade de Comunicação Social do Hospital Universitário da UFPI (HU-UFPI). E-mail: samanthacastelo@gmail.com Cidade: Pelotas.
} 
História oral: reflexões sobre aplicações e implicações | Samantha Castelo Branco

interviewer excels for his dialogical role and can confer the production of knowledge, wealth of detail and depth

Keywords: Oral History; Methodology; Applications; Limits.

\section{Gênese e evolução}

As tecnologias da informação e da comunicação (TICs), no século XXI, geram impactos nos métodos e técnicas de pesquisa, bem como nos instrumentos de coleta de dados utilizados por pesquisadores de diferentes áreas do conhecimento. Acesso a documentos digitalizados, coleta de dados em sites, consulta a bibliotecas virtuais, checagem de informações por whatsapp e realização de entrevistas concedidas por meios digitais ilustram essa nova realidade. Nesse cenário, em meio a variadas perspectivas no que tange aos procedimentos metodológicos utilizados para concretização de estudos científicos, a História Oral (HO) figura entre os caminhos buscados por estudiosos que, por meio da escuta de relatos orais, constroem conhecimento acerca de diversas questões.

A metodologia, que se apoia em depoimentos e testemunhos orais, é aplicada, em pesquisas qualitativas, por meio da realização de entrevistas gravadas com pessoas que vivenciaram acontecimentos do passado e/ou do presente, como sintetiza Alberti (2008, p. 155):

A História Oral é uma metodologia de pesquisa e de constituição de fontes para o estudo da história contemporânea surgida em meados do século XX, após a invenção do gravador a fita. Ela consiste na realização de entrevistas gravadas com indivíduos que participaram de, ou testemunharam, acontecimentos e conjunturas do passado e do presente.

Entre as principais vantagens dessa metodologia de pesquisa, está a possibilidade de incluir, no processo de produção de conhecimento, relatos de fontes normalmente esquecidas, ignoradas ou negligenciadas pela história oficial e por levantamentos tradicionais que se orientam a partir de registros escritos. Nesse sentido, trabalhos realizados a partir de fontes orais permitiram uma concepção ampliada acerca da definição de fontes, sendo, então, possivel a reconstrução de acontecimentos e, também, a construção de narrativas a partir da memória de pessoas que presenciaram tais eventos. 
Definida como "uma arte da escuta" (PORTELLI, 2016), do ponto de vista histórico, a História Oral surge após a Segunda Guerra Mundial, com estreita relação com estes dois fatores: (a) os avanços tecnológicos relacionados a captação, distribuição e armazenamento de áudios e imagens; (b) desejo dos historiadores em registrar as vivências de pessoas como combatentes e sobreviventes perante a guerra (MEIHY, 2002).

Sobre o primeiro fator, vale lembrar que o rádio, durante o segundo conflito mundial, exerceu papel fundamental, devido a sua instantaneidade, tanto no que se refere ao uso militar, como também como meio informativo e, ainda, como recurso para concretizar estratégias de persuasão. Nesse sentido, o aprimoramento de técnicas e tecnologias que permitissem a realização de entrevistas jornalísticas e a difusão de informações foi essencial para o surgimento da HO.

Acerca do segundo fator, é necessária a compreensão de que uma guerra de grandes proporções envolve inéditos e ricos elementos históricos, os quais despertaram nos pesquisadores a intenção de registrá-los por meio de narrativas dos sobreviventes, preservando memórias que poderiam ser revisitadas como alerta para a necessidade de união dos povos e adoção de medidas que evitassem a ocorrência de um novo conflito com semelhantes consequências.

É nesse contexto, que 1947 é tido como o marco do nascimento da História Oral. Meihy (2002) frisa que, nesse ano, Allan Nevis oficializou o termo, ao criar, na Universidade de Colúmbia, em Nova York, um arquivo que serviu de paradigma para a organização, uso e divulgação de dados contidos em entrevistas. Daí em diante, a HO, como metodologia de pesquisa, difundiu-se nos Estados Unidos e, posteriormente, na Europa e no México, tendo ganho, com certa facilidade, adeptos em diferentes áreas, dentre as quais Antropologia, História, Ciência Política e Sociologia.

Paul Thompson, a quem se atribui a introdução do método na Universidade de Essex, na Inglaterra, com o objetivo de coleta de depoimentos de "pessoas comuns", entende que o então uso de aparatos tecnológicos para registros dessas falas pode ser considerada uma novidade, mas que a história oral em si é tão antiga como a própria história (THOMPSON, 2002). 
No âmbito brasileiro, a metodologia foi introduzida na década de 1970, recebendo atenção em polos de estudos como a Universidade de São Paulo (USP) e o Programa de História Oral do Centro de Pesquisa e Documentação de História Contemporânea do Brasil (CPDOC) - Escola de Ciências Sociais da Fundação Getúlio Vargas (FGV).

Logo nas primeiras décadas de aplicação da metodologia no Brasil, a História Oral se sedimenta como:

[...] um método de pesquisa (histórica, antropológica, sociológica, ...) que privilegia a realização de entrevistas com pessoas que participaram de, ou testemunharam acontecimentos, conjunturas, visões de mundo, como forma de se aproximar do objeto de estudo. Trata-se de estudar acontecimentos históricos, instituições, grupos sociais, categorias profissionais, movimentos, etc. (ALBERTI, 1990. p. 52).

Aos poucos, a História Oral foi sendo incorporada como método de pesquisa em variadas áreas do conhecimento, ganhando aplicação inicial em estudos interdisciplinares, especialmente aqueles que envolviam, como citado por Alberti (1990), estudiosos advindos da História, da Sociologia e da Antropologia.

A partir dos anos de 1990, houve um maior interesse no Brasil, por parte dos pesquisadores, em torno da História Oral, o que culminou com a criação, em 1994, da Associação Brasileira de História Oral, que congrega membros de todas as regiões do país, os quais se reúnem, periodicamente, em encontros nacionais e regionais, editando, ainda, revista e boletim. Em 1996, foi criada a Associação Internacional de História Oral, que realiza congressos bianuais, oportunidade para discussões em torno da produção sobre essa metodologia e acerca dos resultados de estudos nos quais houve sua aplicação, o que vem sendo observado em produções que vão além das áreas já mencionadas, abrangendo, também, trabalhos realizados por profissionais de campos como Enfermagem, Arquitetura e Urbanismo, Letras, Geografia Humana e Jornalismo.

Diante do exposto, objetiva-se abordar a HO como opção metodológica no âmbito de pesquisas qualitativas, bem como refletir sobre suas aplicações e implicações, além de problematizar aspectos éticos e 
História oral: reflexões sobre aplicações e implicações | Samantha Castelo Branco

técnicos relacionados a essa metodologia. Para isso, é mister ressaltar que a História Oral, na literatura acerca do assunto, já foi classificada como método, técnica e teoria. Na atualidade, como registra Penna (2005), é adequado considerá-la como metodologia de pesquisa.

\section{Tipos de História Oral}

Autores como Meihy (2002) apontam a existência de três tipos de História Oral: (a) História Oral de Vida; (b) História Oral Temática; (c) Tradição Oral.

No que se refere à primeira modalidade, permite-se que o sujeito tenha assegurada maior autonomia para expor, o mais livremente possivel, experiências pessoais, sendo a ele dado espaço para que sua narrativa seja conduzida segundo a própria vontade. Queiroz (1988, p. 20) destaca que "a história de vida se define como o relato de um narrador sobre a sua existência através do tempo, tentando reconstituir os acontecimentos que vivenciou e transmitir a experiência que adquiriu".

É importante, a partir daí, pontuar que a História Oral de Vida se distingue tanto da biografia como da autobiografia, uma vez que, na primeira, são ressaltados aspectos marcantes da existência de um indivíduo sobre quem se decidiu escrever e, no segundo caso, não há sequer a presença e atuação do pesquisador como participante necessário ao processo.

Em se tratando da História Oral Temática, busca-se, a partir de um assunto específico, a narrativa de um entrevistado sobre evento definido, preestabelecido. Os detalhes da vida do narrador e as experiências pessoais adquirem interesse à medida que revelam aspectos vinculados à temática central.

Já a Tradição Oral, de acordo com Meihy (2002), tem como foco a visão de mundo de comunidades que têm valores filtrados por estruturas mentais asseguradas em referências do passado remoto, que se manifestam pelo folclore e pela transmissão geracional.

Para melhor compreensão desses tipos, algumas de suas características estão elencadas no Quadro 1. 
Quadro 1

História Oral - Tipos

\begin{tabular}{|c|c|c|}
\hline História Oral de Vida & História Oral Temática & Tradição Oral \\
\hline $\begin{array}{l}\text { - Sujeito primordial: depoente } \\
\text { (narrador). } \\
\text { - Valorização do relato ou da } \\
\text { versão apresentada pelo } \\
\text { narrador. } \\
\text { - A entrevista é realizada com } \\
\text { base em tópicos ou perguntas } \\
\text { amplas, de forma a permitir a } \\
\text { abordagem de experiências } \\
\text { pessoais do entrevistado, } \\
\text { segundo a sua vontade. } \\
\text { - O pesquisador/entrevistador } \\
\text { não contesta a narrativa. }\end{array}$ & $\begin{array}{l}\text { - A atuação do } \\
\text { pesquisador/entrevistador é } \\
\text { mais explícita e fica } \\
\text { evidenciada na pesquisa. } \\
\text { - O pesquisador tem um papel } \\
\text { ativo, inclusive sendo a ele } \\
\text { possibilitada a contestação. } \\
\text { - A entrevista é utilizada pelo } \\
\text { pesquisador mais como um } \\
\text { documento para a busca de } \\
\text { esclarecimentos acerca de uma } \\
\text { temática central, previamente } \\
\text { selecionada. } \\
\text { - Centra-se em um assunto } \\
\text { específico e preestabelecido, } \\
\text { objetivando-se narrativa do } \\
\text { entrevistado vinculada a esse } \\
\text { acontecimento. } \\
\text { - Detalhes da vida pessoal do } \\
\text { narrador adquirem interesse } \\
\text { apenas se vinculados à } \\
\text { temática central. }\end{array}$ & $\begin{array}{l}\text { - Tem como ênfase a visão de } \\
\text { mundo de comunidades que } \\
\text { têm valores filtrados por } \\
\text { estruturas mentais asseguradas } \\
\text { em referências do passado } \\
\text { remoto. } \\
\text { - Perpassa questões que se } \\
\text { manifestam pelo folclore e pela } \\
\text { transmissão geracional. } \\
\text { - A narrativa do entrevistado } \\
\text { adquire caráter mais coletivo } \\
\text { que individual. } \\
\text { - A entrevista deve ser } \\
\text { realizada com pessoas que } \\
\text { sejam depositárias das } \\
\text { tradições de tribos, } \\
\text { comunidades, clãs ou outros } \\
\text { grupos. }\end{array}$ \\
\hline
\end{tabular}

Fonte: Adaptado de Meihy (2002).

\section{Aplicações e implicações}

A História Oral, na avaliação de Carneiro (2012), deve ser vista como importante ferramenta por buscar compreender as transformações ou mudanças que ocorrem na sociedade, em um grupo social ou mesmo no modo de vida das pessoas. Assim, permite o entendimento de valores culturais, espirituais e sociais cultivados por um agrupamento humano.

Segundo Philippe Joutard (1999, p. 151), é possivel elencar, originalmente, três motivos que fomentam o fazer da História Oral: (a) "Escuchar la voz de los excluídos"; (b) "Sacar a la luz las realidades 
indescriptibles"; (c) "Dar testimonios de las situaciones de sufrimiento extremo".

Embora a $\mathrm{HO}$ e, também, o uso de gravador na captação de relatos orais, não constituam novidade entre os pesquisadores, o método permanece em foco especialmente por possibilitar a manifestação de fontes normalmente excluidas dos relatos oficiais, como pontua Guedes-Pinto:

A HO preocupa-se, fundamentalmente, em criar diversas possibilidades de manifestação para aqueles que são excluídos da história oficial, tanto a "tradicional" quanto a contemporânea, e que não possuem formas suficientemente fortes para o enfrentamento das injustiças sociais (GUEDES-PINTO, 2002, p. 95).

$\mathrm{Na}$ atualidade, autores propõem um repensar em torno da ideia de que a História Oral se volte apenas a "escutar a voz dos excluídos", a partir do entendimento de que essa premissa foi evidenciada em dado contexto e sustentada em recortes histórico-sociais específicos. Encontra-se, portanto, na literatura sobre a temática, menções à aplicação dessa metodologia de pesquisa à história da elite (JOUTARD, 2000).

Outro aspecto positivo da $\mathrm{HO}$ encontra-se no fato de permitir a coleta de informações que impulsionam a produção de conhecimento sobre diferentes objetos de estudo:

[...] a história oral pode dar grande contribuição para o resgate da memória nacional, mostrando-se um método bastante promissor para a realização de pesquisa em diferentes áreas. É preciso preservar a memória física e espacial, como também descobrir e valorizar a memória do homem. A memória de um pode ser a memória de muitos, possibilitando a evidência dos fatos coletivos (THOMPSON, 2002, p. 17).

Concebida como metodologia de pesquisa que se apoia em testemunhos e relatos sobre acontecimentos, conjunturas, instituições, modos de vida ou outros aspectos da história, a História Oral apresenta, de plano, variadas aplicações:

As perspectivas de pesquisa são, pois, múltiplas. No caso das histórias de vida e dos depoimentos pessoais, podem estes ser utilizados para esclarecer a existência, os processos mentais, as características psicológicas de determinado indivíduo; somente estaria então em causa a reconstrução daquela existência, ou do fato sobre o qual se solicitou explicitamente o testemunho do informante (QUEIROZ, 1991, p. 94).

De acordo com Delgado (2006), a HO é um procedimento metodológico que, por meio de entrevistas, produz narrativas de pessoas que 
testemunharam acontecimentos tanto na vida privada quanto coletiva, ou seja, tais narrativas estão atreladas às memórias dos entrevistados.

A História Oral é, assim, visivelmente associada à noção de memória por aqueles que a compreendem como sendo como método de pesquisa baseado no registro de depoimentos orais concedidos em entrevistas (JOUTARD, 2006).

Nessa linha de pensamento, a História Oral centra-se na memória humana e sua capacidade de rememorar o passado enquanto testemunha do vivido. Entende-se memória como a presença do passado, como uma construção psiquica e intelectual de fragmentos representativos desse mesmo passado, nunca em sua totalidade, mas parciais em decorrência dos estímulos para a sua seleção.

Na visão de Maurice Halbwachs (2004), toda memória é coletiva e, como tal, constitui um elemento essencial da identidade, da percepção de si e dos outros. Por outro lado, a literatura, como assinala Viana (2006), oferece críticas ao conceito de memória coletiva, embora reconhecendo sua importância em um dado momento histórico. Pensar a memória como social é tarefa assumida por autores com significativas contribuições sobre a temática, a exemplo de Candau (2011).

Emerge daí a principal contribuição da História Oral como metodologia que guarda em si a capacidade de recuperar a memória em torno de objetos de estudos que nem sempre oferecem documentos escritos e materiais. A oralidade, então, se apresenta como o meio de compreensão de fatos do passado.

Entretanto, é mister ressaltar que o resgate do passado por meio da oralidade esbarra no fato de que as lembranças dos indivíduos são permeadas por influências coletivas, passam por filtros, são resignificadas ao ultrapassar a esfera do íntimo (privado) para o coletivo (público).

A memória é um processo individual, que ocorre em um meio social dinâmico, valendo-se de instrumentos socialmente criados e compartilhados. Em vista disso, as recordações podem ser semelhantes, contraditórias ou sobrepostas. Porém, em hipótese alguma, as lembranças de duas pessoas são - assim como as impressões digitais, ou, a bem verdade, como as vozes - exatamente iguais (PORTELLI, 1997, p. 16). 
História oral: reflexões sobre aplicações e implicações | Samantha Castelo Branco

Por sua vez, Pollak (1992) destaca, ainda, que a memória é seletiva. Nem tudo fica gravado, nem tudo se registra. O caráter seletivo da memória é reforçado pela noção de pertencimento afetivo ao grupo ao qual um determinado indivíduo encontra-se inserido, pois o sentimento de continuidade presente naquele que se lembra é o que faz com que uma dada memória permaneça.

Alguns autores, a exemplo de Fentress e Wickham (1992) e Errante (2000), observam que a "dependência da memória" é uma marca característica da História Oral. Isto porque as narrativas orais são, por natureza, narrativas de memória. Nesse ponto específico, Antoinette Errante (2000) ressalta que o pesquisador precisa ser crítico em relação ao significado que há por trás de memórias particulares coletadas durante um trabalho de HO.

Recomenda-se, então, que alguns questionamentos sejam adotados pelo pesquisador, como:

a) Qual o significado dessas memórias para o entrevistado?

b) Qual(is) a(s) relação(ões) existente(s) entre o que é rememorado pelo entrevistado com sua própria vida, sua existência e sua trajetória?

c) As memórias externas estão permeadas de que sentimentos?

Tais questionamentos auxiliam na análise que o pesquisador realiza diante dos conteúdos gerados a partir dos relatos orais e permitem que o conhecimento produzido não se vista da pretensão de construir uma história única, absoluta ou totalizante, uma vez que, como entende Portelli (1997, p. 25), “[...] até mesmo erros, invenções e mentiras constituem, à sua maneira, áreas onde se encontra a verdade”.

Surgem, então, a partir dessas colocações, implicações decorrentes do uso da História Oral como metodologia de pesquisa, que podem originar preocupações a serem observadas a partir de três aspectos, que serão detalhados a seguir:
a) subjetividade das fontes;
b) interferência do pesquisador;
c) aplicação da $\mathrm{HO}$ a abordagens de fatos passados. 


\section{I Subjetividade das fontes}

A subjetividade das fontes ditas orais é aspecto explorado por Paul Thompson (2002). O autor explica que nenhuma fonte está livre da subjetividade, seja ela escrita, oral ou visual. Correm o risco de ser insuficientes, ambíguas ou até mesmo passiveis de manipulação. Apesar da subjetividade a que a fonte oral está sujeita, o autor argumenta em prol do uso da História Oral:

Toda fonte histórica derivada da percepção humana é subjetiva, mas apenas a fonte oral permite-nos desafiar a subjetividade: descolar as camadas da memória, cavar fundo em suas sombras, na expectativa de atingir a verdade oculta. Se assim é, porque não aproveitar essa oportunidade que só nós temos entre os historiadores, e fazer nossos informantes se acomodarem relaxados no divã, e, como psicanalistas, sorver em seus inconscientes, extrair os mais profundos de seus segredos? (THOMPSON, 2002, p. 197).

Thompson frisa que "a evidência oral pode conseguir algo mais penetrante e mais fundamental para a história" (THOMPSON, 2002, p. 137), uma vez que tem o potencial de transformar os objetos de estudos em sujeitos.

Nesse processo de transformação dos objetos estudados historicamente em sujeitos, etapas que antecedem a realização da entrevista (levantamento de dados preliminares que possam embasar as entrevistas, seleção das fontes e escolha do tipo de entrevista a ser utilizada) contribuem para o êxito da metodologia em estudo.

A subjetividade e a confiabilidade das fontes são aspectos também discutidos por autores como Alessandro Portelli (2006). Para ele, as fontes orais revelam as intenções dos feitos, crenças, mentalidades, imaginário e pensamentos referentes às experiências vividas. Em seu entendimento, ainda que a fonte oral não gere dados precisos, possui dados que, às vezes, um documento escrito não oferece, impondo-se como essencial para compreensão e estudo de determinados objetos / temáticas. Por meio dela, se pode conhecer os sonhos, anseios, crenças e lembranças do passado de pessoas anônimas, simples, sem nenhum status politico ou econômico, mas que viveram os acontecimentos de sua época. 
Essa disposição para compreender o "outro" deve, na visão de Priscila David (2013, p. 161), ser assumida pelo pesquisador:

\begin{abstract}
Nesta esteira, trabalhar com a História oral traz ao historiador a necessidade de reconhecer sua subjetividade e, diante disso, de se aprofundar em uma metodologia que demanda a interdisciplinaridade e a crítica constante das fontes. Neste trabalho, o historiador deve, antes de tudo, dominar as técnicas de um diálogo que visa compreender o outro.
\end{abstract}

Assim, como tentativa de minimizar a subjetividade das fontes, autores como Eva Lakatos e Marina Marconi (2010) aconselham a combinação de metodologias possiveis em uma mesma pesquisa. No caso específico da História Oral, fontes escritas podem ser consultadas por meio de pesquisa bibliográfica e/ou documental. No decorrer do estudo, o diálogo entre a documentação escrita já existente e a fonte oral conduzem o pesquisador a caminhos mais acertados, fazendo com que compreenda melhor o que a testemunha/o entrevistado quis expressar e quais os motivos para o que relatou.

Em reforço a essa sugestão, Nora (1993) - ao afirmar que a memória é a base constituidora da oralidade, mas pode não apresentar precisão, uma vez que está constantemente ajustada às crenças e imaginários dos indivíduos - também admite que a fonte oral seja confrontada com outros tipos de documentação e analisada não apenas como complementação do documento escrito nos estudos históricos. Lembra que ambos produzem informações sobre as transformações das sociedades humanas.

Ricardo Santhiago (2008, p. 33) procura resumir esse debate:

Desde que a história oral ousou extrapolar a condição de fonte, desejando alçar autonomia disciplinar, tem sido chamada a assumir posições em diferentes debates que, via de regra, concentram um único objetivo: questionar a legitimidade da fonte oral, do historiador oral e do documento proveniente de seu trabalho.

Nesse ponto, é oportuno mencionar que a discussão sobre a subjetividade das fontes como premissa para legitimar ou não a História Oral, encontra-se, atualmente, mitigada, até mesmo face à constatação que toda fonte passa por seleções e, ao ter seu conteúdo trabalhado pelo pesquisador, estará vinculada a uma interlocução de subjetividades (GEERTZ, 2005). 
Como expõe Verena Alberti, em entrevista veiculada no site do Centro de Referência da Educação Pública (2007), "Antigamente, dizia-se que uma entrevista de história oral estava imbuída de subjetividade e que o entrevistado poderia 'distorcer' a realidade. Hoje já se considera a subjetividade e a própria 'distorção' da realidade como objetos importantes para o estudo da história e das representações do passado".

\subsection{Interferência do pesquisador}

As entrevistas de História Oral podem ser entendidas como técnicas de coleta de informações que, ao serem transcritas, constituem importantes fontes para a compreensão de temáticas e objetos de estudo, especialmente se combinadas com outras fontes, a exemplo de documentos escritos, materiais e sonoros. Tais entrevistas são realizadas a partir da iniciativa do pesquisador, que procura o entrevistado para tal fim.

Porém, antes mesmo desse contato, a partir de pontuações feitas por Thompson (2002), Alberti (2005), Portelli (2016) e Zago (2003), é importante que o pesquisador:

a) tenha consciência de que sua completa neutralidade não existe, uma vez que sua marca no estudo se sedimenta desde a escolha do objeto e passa pelo tipo de entrevista a ser realizada. As fontes orais são, assim, "cocriadas" a partir da relação entre entrevistador e entrevistado.

b) respeite as exigências e princípios estabelecidos pelo comitê de ética da instituição a que a pesquisa está vinculada, inclusive aqueles que se referem ao Termo de Consentimento Informado;

c) tenha em mente que, embora seu estudo gere resultados e conclusões, esses podem ser aprofundados e revistos, inclusive por outros estudiosos;

d) entenda que a entrevista utilizada na $\mathrm{HO}$ não exige uma estrutura rígida, optando, portanto, por um roteiro flexível, em que as questões previamente definidas podem sofrer alterações no decorrer do depoimento da fonte; 
e) construa fichas e/ou arquivos que permitam a organização das fontes orais, incluindo dados como nome do entrevistado, idade, endereço, profissão.

A opção pela História Oral exige do pesquisador um conjunto de providências anteriores e posteriores à gravação dos depoimentos. Antes, pode-se citar a pesquisa bibliográfica e/ou documental para melhor aprofundamento das questões a serem elencadas em torno do assunto e o levantamento de dados para a seleção dos sujeitos a serem buscados como fontes. Cumpridas essas etapas, o pesquisador pode preparar o roteiro das entrevistas, se for o caso, e agendar data e local para o encontro.

A relação entre pesquisador e entrevistado merece especial atenção quando da opção pela História Oral. A produção de conhecimento requer que essa relação se defina em medida ajustada, que afasta qualquer possibilidade de ocupação, por parte do entrevistador, de uma posição de superioridade. Como previne Bourdieu (1998, p. 701), essa postura deve ser evitada para que se afaste a ocorrência de violência simbólica durante a entrevista: “[...] a relação social entre pesquisado e pesquisador produz um efeito de censura muito forte, redobrado pela presença do gravador; é sem dúvida ela que torna certas opiniões inconfessáveis (salvo por breves fugas ou lapsos)".

Nesse sentido, recomenda-se ao pesquisador que:

a) exponha ao entrevistado, com clareza, os objetivos da pesquisa e de que modo seu relato pode contribuir para os objetivos propostos;

b) defina, com aprovação do entrevistado, o ambiente em que se dará a entrevista, preocupando-se com o conforto da fonte e, ainda, com a possibilidade de o local escolhido manter relação com os fatos narrados ou com a temática a ser enfocada, o que auxiliará na rememoração dos episódios vivenciados;

c) evite invadir a privacidade do entrevistado, respeitando a negativa da fonte em responder questões que eventualmente o levem a relembrar momentos que ele deseja esquecer;

d) esteja atento às respostas do entrevistado e aos momentos adequados para fazer intervenções ou iniciar novas questões; 
e) aja de maneira natural e menos forçada possível, externando ao entrevistado a disposição por ouvi-lo e compreendê-lo.

Essas orientações estão em sintonia com o que defende Zago (2003) ao destacar que a riqueza do material obtido para o estudo, embora considere a importância das técnicas de condução da entrevista, depende, prioritariamente, da capacidade do pesquisador de obter a confiança dos sujeitos pesquisados.

Ainda no que se refere ao processo de coleta de informações, por sugestão de Silveira (2007), é válido ter um diário de campo no qual o pesquisador possa registrar anotações das reações, posturas e impressões do entrevistado, além de dificuldades enfrentadas.

Durante a realização da entrevista, o uso do aparelho gravador - que atualmente pode ser substituído face a oferta de aplicativos para gravação de áudio em celular - ganha reflexões a partir do pensamento de Maria Isaura Pereira de Queiroz (1991). A autora desmitifica o uso da tecnologia como forma de garantir a objetividade. Afirma que as subjetividades permeiam todo o processo, desde o registro aos usos. Por mais que não haja interferências durante a gravação, quando o estudioso se volta para o aproveitamento do material que colheu, a subjetividade e as emoções se fazem presentes:

Os meios mecânicos são enaltecidos porque permitem um afastamento do pesquisador e de sua subjetividade na coleta dos dados; possibilitam, desta forma, dados muito mais próximos da realidade, sem a distorção trazida pelas emoções dos estudiosos. Porém, no momento em que o estudioso se volta para o aproveitamento do material que colheu, então a subjetividade e as emoções se tornariam fundamentais... (QUEIROZ, 1991, p. 94).

De acordo com Alberti (2005), um dos equivocos mais comuns durante a pesquisa se refere à postura de cientistas que tendem a considerar a entrevista como a própria história. Na verdade, o estudioso, ao optar pela História Oral, deve, após a realização da entrevista, transcrevê-la e, ainda, ao interpretar e analisar o seu conteúdo, considerá-la como fonte oral. Sobre esse aspecto, Pierre Nora (1993) explica que o historiador da oralidade é criador da própria fonte, uma vez que a entrevista precisa ser extraída da testemunha e somente se torna fonte após a transcrição. 
Por sua vez, a decupação ou transcrição das entrevistas deve merecer especial atenção do pesquisador, de forma a preservar o conteúdo do relato oral, ainda que o investigador faça cruzamentos posteriores com informações advindas de outras fontes. A interferência do pesquisador, no sentido de efetuar modificações nos depoimentos, é uma preocupação de Queiroz (1991), para quem o relato de cada informante só teria valor de informação se apresentado ao público em sua totalidade, assim como gravado.

Embora a transcrição deva guardar fidelidade com o que foi dito no relato oral, possibilita-se a edição de palavras ou trechos para que, como ressalta Bourdieu (1998), o texto seja aliviado de redundâncias verbais, tiques de linguagem e frases confusas.

Ante o exposto, mesmo ciente da possibilidade de interferência no processo, o pesquisador deve nortear a etapa de transcrição dos relatos a partir de algumas regras prescritas por Matos e Senna (2011): (a) a transcrição deve ser feita pelo próprio entrevistador, o quanto antes, sem que permita um grande espaço temporal entre a data da realização da entrevista e a da decupação; (b) as passagens pouco audiveis devem ser colocadas entre colchetes no texto já transcrito; (c) dúvidas e silêncios devem ser assinalados por reticências; (d) as palavras de forte entonação devem ser colocadas em negrito; (e) risos devem ser destacados, com grifos.

Após a transcrição, as entrevistas podem servir de fonte para outros pesquisadores. A gravação deve ser arquivada, uma vez que é o documento original que se deve consultar em caso de dúvida.

3.3 Aplicação da $\mathrm{HO}$ a abordagem de fatos passados

Uma questão importante envolvendo a História Oral refere-se ao fato dessa metodologia ter sua utilização reduzida a pesquisas que versam sobre temas contemporâneos, cabendo, sobre isso, citar Pierre Nora:

A memória é um fenômeno sempre atual, um elo vivido no eterno presente; a história, uma representação do passado. Porque é afetiva e mágica, a memória não se acomoda a detalhes que a confortam: ela se alimenta de lembranças vagas, telescópicas, globais ou flutuantes, particulares ou simbólicas, sensivel a todas as transferências, cenas, censuras ou projeções. A história, porque operação intelectual e laicizante, demanda análise e discursos críticos. A memória instala a lembrança no sagrado, a história a liberta e a torna sempre prosaica [...] (NORA, 1993, p. 9). 
A crítica à aplicação da HO somente a temas contemporâneos tende a ser atenuada à medida que se formam arquivos especializados em fontes orais, os quais guardam gravações e transcrições de testemunhas. Esses arquivos possibilitam a pesquisa e estudos de tempos passados e não necessariamente do presente. Assim, em sintonia com o que coloca Alberti (2004, p. 23), ao frisar que a História Oral possibilita a "recuperação do vivido, concebido por quem viveu", os estudos por meio da oralidade centrados em fatos do passado dependem dessa organização.

Dessa forma, o uso da História Oral em investigações - sejam acerca do passado, sejam sobre o presente - e seu consequente êxito dependem, portanto, do conhecimento prévio, por parte do pesquisador, das questões tratadas acima. Essa consciência permitirá ao estudioso uma análise mais segura acerca da adequação dessa metodologia de pesquisa ao alcance dos objetivos traçados por ele.

\section{Quadro 2}

História Oral - aplicações e implicações

\begin{tabular}{|c|c|}
\hline Aplicações & Implicações \\
\hline $\begin{array}{l}\text { - permite a compreensão das } \\
\text { transformações ou mudanças que ocorrem } \\
\text { na sociedade, em um grupo social ou mesmo } \\
\text { no modo de vida das pessoas. } \\
\text { - possibilita a manifestação de fontes } \\
\text { normalmente excluídas dos relatos oficiais. } \\
\text { - pode ser utilizada em pesquisas de } \\
\text { diferentes áreas do conhecimento. }\end{array}$ & $\begin{array}{l}\text { - lembranças dos indivíduos são permeadas } \\
\text { por influências coletivas, passam por filtros, } \\
\text { são ressignificadas ao ultrapassar a esfera do } \\
\text { íntimo (privado) para o coletivo (público). } \\
\text { - o sujeito primordial é o depoente. O } \\
\text { narrador é soberano para revelar ou ocultar } \\
\text { casos, situações e pessoas em sua narrativa. } \\
\text { No entanto, esse aspecto não afasta o } \\
\text { emprego da metodologia, sendo, inclusive, } \\
\text { uma característica expressiva na modalidade } \\
\text { História Oral de Vida. } \\
\text { - caráter seletivo da memória. } \\
\text { - interferência do pesquisador durante as } \\
\text { fases de realização de entrevistas, } \\
\text { decupação e interpretação. Vale ressaltar } \\
\text { que a questão da subjetividade não é } \\
\text { considerada um entrave, na atualidade, para } \\
\text { a aplicação da Ho. }\end{array}$ \\
\hline
\end{tabular}

Fonte: CASTELO BRANCO, 2020. 
Além da necessidade de conhecimento desses aspectos, Maria Isaura Queiroz (1991, p. 106) entende que é necessário que o pesquisador visualize que sua atividade não deve se encerrar exatamente com as conclusões geradas pela pesquisa:

Os resultados do cotejo acima exposto permitem também avaliar criticamente se a marcha adotada na realização da pesquisa foi satisfatória em seus diversos passos: a) se as questões propostas pelo pesquisador em seu projeto podem realmente ser esclarecidas pelo procedimento que adotou na realização da pesquisa; b) se a escolha dos informantes foi válida para os problemas então colocados; c) quais os problemas não delineados no projeto, mas que as informações dos depoentes mostram existir; d) se as técnicas empregadas foram satisfatórias para se alcançar alguns resultados, se foram suficientes; e) se a abordagem empregada aponta outras técnicas que seriam igualmente necessárias a fim de complementar de maneira eficiente as informações obtidas.

Deve o pesquisador avaliar, portanto, em uma postura crítica, os procedimentos adotados, gerando, assim, novas possibilidades de estudo, aprimorando a metodologia da História Oral e permitindo que esta possa ser aplicada de forma a gerar conhecimento em diversas áreas de estudo, em diferentes tempos, sobre variados objetos.

\section{Considerações finais}

A História Oral vem sendo aplicada a estudos realizados em diferentes áreas do conhecimento. No entanto, a adoção dessa metodologia requer, por parte do pesquisador, uma cuidadosa análise para conferir sua adequação ao objeto de estudo que motiva e direciona a investigação. Para isso, é essencial que o investigador conheça as variadas aplicações da HO, incluindo-se a possibilidade de compreensão das transformações que ocorrem na sociedade, em um grupo social ou mesmo no modo de vida das pessoas e, ainda, a inclusão, em estudos de natureza científica, de fontes normalmente excluidas dos relatos oficiais.

Entretanto, especialmente por ser uma metodologia que envolve a oralidade e que depende da memória dos indivíduos ouvidos, a História Oral gera implicações ou esbarra em determinadas questões que devem ser de conhecimento do pesquisador. Algumas delas dizem respeito à subjetividade das fontes e ao caráter seletivo da memória.

Nesse sentido, para que a metodologia em questão contribua com a qualidade do conhecimento produzido, é necessário que o pesquisador adote 
História oral: reflexões sobre aplicações e implicações | Samantha Castelo Branco

procedimentos antes, durante e após a entrevista. Entre eles, pode-se citar a elaboração de um roteiro flexível, que possa ser modificado no decorrer da entrevista; o afastamento de qualquer conduta que possa gerar uma postura de superioridade face ao entrevistado, mas, ao contrário, procure estabelecer uma relação de confiança e respeito mútuo com a fonte; e a transcrição fidedigna dos áudios gravados.

Além disso, o trabalho realizado a partir da História Oral deve contar com um pesquisador que, consciente das implicações decorrentes da utilização dessa metodologia, exercite sua sensibilidade e prime pelo seu papel dialógico, a fim de conferir, à produção do conhecimento, riqueza e profundidade.

\section{Referências:}

ALBERTI, Verena. História Oral: a experiência do CPDOC. Rio de Janeiro: Fundação Getúlio Vargas, 1990.

ALBERTI, Verena. Manual de História Oral. 3.ed. Rio de Janeiro: FGV, 2005.

ALBERTI, Verena. Fontes orais: História dentro da História. In: PINSKY, Carla Bassanezi (Org.). Fontes Orais. 2. ed. São Paulo: Contexto, 2008. p. 155-202.

BOURDIEU, Pierre. Compreender. In: BOURDIEU, Pierre (Coord.). A miséria do mundo. 2. ed. Petrópolis: Vozes, 1998, p.693-713.

CANDAU, Joël. Memória e identidade. São Paulo: Contexto, 2011.

CARNEIRO, Josué. História Oral Como Instrumento no Desenvolvimento e Elaboração da Pesquisa. Boletim de Geografia, Maringá, v. 30, n. 2, p. $121-131,2012$.

CENTRO DE REFERÊNCIA DA EDUCAÇÃO PÚBLICA. História Oral. Entrevistada: Verena Alberti. CREP, Rio de Janeiro, 09/10/2007. Disponivel em: <http://www0.rio.rj.gov.br/sme/crep/entrevistas/verena_alberti.htm>. Acesso em: 05/06/2020.

DAVID, Priscila. História Oral: Metodologia do Diálogo. Patrimônio e Memória. São Paulo, Unesp, v. 9, n. 1, p. 157-170, janeiro-junho, 2013.

DELGADO, Lucilia de Almeida Neves. História Oral: memória, tempo identidades. Belo Horizonte: Autêntica, 2006. 
História oral: reflexões sobre aplicações e implicações | Samantha Castelo Branco

ERRANTE, Antoinette. Mas afinal, a memória é de quem? Histórias Orais e Modos de Lembrar e Contar. História da Educação/ASPHE. Pelotas: UFPel, n. 8, p. 140-174, 2000.

FENTRESS, James; WICKHAM, Chris. Social memory: new perspectives on the past. Cambridge: Blackwell, 1992.

GEERTZ, C. Obras e Vidas: O antropólogo como autor. Rio de Janeiro: UFRJ, 2005.

GUEDES-PINTO, Ana Lúcia. Rememorando trajetórias da professoraalfabetizadora: a leitura como prática construtiva de sua identidade e formação profissionais. Campinas-SP: Mercado de Letras, 2002.

HALBWACHS, Maurice. A memória coletiva. São Paulo: Centauro, 2004.

JOUTARD, Philippe. Nuevas polémicas sobre Historia Oral: algunos retos que se le plantean a la Historia Oral del Siglo XXI. In: Historia, Antroplogia y Fuentes Orales, no. 21, 1999.

JOUTARD, Philippe. Desafios à história oral do século XXI. In: FERREIRA, Marieta de Moraes; FERNANDES, Tania Maria; ALBERTI, Verena (Orgs.). História Oral: desafios para o século XXI. Rio de Janeiro: Ed. Fiocruz/Casa de Oswaldo Cruz/CPDOC-FGV, 2000. p.31-45.

JOUTARD, Philippe. História oral: balanço da metodologia e da produção nos últimos 25 anos. In: FERREIRA, M. M.; AMADO, J. (Org.). Usos e abusos da História Oral. Rio de Janeiro: Fundação Getúlio Vargas, 2006. p. 43-62.

LAKATOS, E. Maria; MARCONI, M. de Andrade. Fundamentos de metodologia científica: técnicas de pesquisa. 7. ed. São Paulo: Atlas, 2010.

MATOS, Júlia Silveira; SENNA, Adriana Kivanski. História oral como fonte: problemas e métodos. Historiae, Rio Grande, n.2, p. 95-108, 2011.

MEIHY, José Carlos Sebe Bom. Manual de História Oral. 4. ed. São Paulo: Loyola, 2002.

MEIHY, José Carlos Sebe Bom. Os novos rumos da história oral: o caso brasileiro [Online]. Revista de História. São Paulo: Universidade de São Paulo, 2006. $\quad$ p. $191-203 . \quad$ Disponivel em: <https://www.redalyc.org/pdf/2850/285022045011.pdf>. Acesso em: 23/03/2020.

NORA, Pierre. Entre memória e história: a problemática dos lugares. Projeto História, n. 10. São Paulo: PUC, dez. 1993. p. 7-28.

PENNA, Rejane Silva. Fontes orais e historiografia: avanços e perspectivas. Porto Alegre: Edipucrs, 2005. 
História oral: reflexões sobre aplicações e implicações | Samantha Castelo Branco

POLlAK, M. Memória e identidade social. Estudos Históricos, Rio de Janeiro, v. 5, n. 10, 1992. p. 200-212.

PORTELLI, Alessandro. Tentando aprender um pouquinho. Algumas reflexões sobre a ética na história oral. Projeto História, São Paulo, n. 15, p.13-49, abr. 1997.

PORTELLI, Alessandro. História Oral como Gênero. Projeto História, São Paulo, n. 22, p. 9- 36, jun., 2001.

PORTELLI, Alessandro. O massacre de Civitella Val di Chiana (Toscana: 29 de junho de 1944): mito, política, luta e senso comum. In: FERREIRA, M. M.; AMADO, J. (Org.). Usos e abusos da história oral. Rio de Janeiro: Fundação Getúlio Vargas, 2006.

PORTELLI, Alessandro. História Oral como arte da escuta. Trad. Ricardo Santhiago. São Paulo: Letra e Voz, 2016.

QUEIROZ, Maria Isaura Pereira de. Relatos orais: do "indizivel" ao "dizivel". In: VON SIMON, Olga de Moraes (Org.). Experimentos com histórias de vida (Itália-Brasil). São Paulo: Vértice, 1988. p. 14-43.

QUEIROZ, Maria Isaura Pereira de. Variações sobre a técnica de gravador no registro da informação viva. São Paulo: T.A. Queiroz, 1991.

SANTHIAGO, Ricardo. Da fonte oral à história oral: debates sobre legitimidade. Saeculum - Revista de História. n. 18. João Pessoa, jan/ jun. 2008. p. 33-46.

SILVEIRA, Éder da Silva. História Oral e memória: pensando um perfil de historiador etnográfico. MÉTIS: história \& cultura. v. 6, n. 12, p. 35-44, jul./dez. 2007. p. 35-44.

THOMPSON, Paul. A voz do passado: História Oral. 3.ed. Rio de Janeiro RJ: Paz e Terra, 2002.

VIANA, Nildo. Memória e sociedade: uma breve discussão teórica sobre memória social. Espaço Plural. Ano VI, n. 14, $1^{\circ}$ sem. 2006. p. 8-10. Versão eletrônica disponivel em: www.unioeste.br/saber. Acesso em 04/06/2020.

ZAGO, Nadir. A entrevista e seu processo de construção: reflexões com base na experiência prática da pesquisa. In: ZAGO, Nadir et al. Perspectivas qualitativas em sociologia da educação. Rio de Janeiro: DP\&A, 2003. 